\section{Edycaçäa

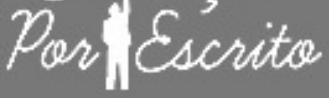

ARTIGO

\section{Editor}

Alexandre Anselmo Guilherme PUCRS, RS, Brasil

\section{Editor Assistente}

Cibele Cheron

PUCRS, RS, Brasil

\section{Editores Associados}

Bruno Antonio Picoli

Universidade Federal da Fronteira Sul, Chapecó, SC, Brasil

Pricila Kohls dos Santos Universidade Católica de Brasília, Brasília, DF, Brasil

Renato de Oliveira Brito

Universidade Católica de Brasilia, Brasilia, DF, Brasil

Elisa Ustarroz

PUCRS, Porto Alegre, RS, Brasil

\section{ISSN 2179-8435}

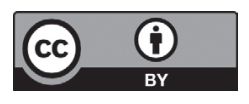

Este artigo está licenciado sob forma de uma licença Creative Commons Atribuição 4.0 Internacional, que permile uso irrestrito, distribuiçăo e reprodução seja corretamente citada http://creativecommons.org/licenses/by/4.0/deed.pt_BR

\title{
(Auto)produção na profissão docente: olhares a partir dos portfólios de aprendizagem do estágio
}

\author{
(Auto)production in the teaching profession: looks from the
} learning portfolios of the stage

Kessia Mileny de Paulo Moura $\oplus^{1}$

Marie Jane Soares de Carvalho ${ }^{2}{ }^{2}$

Renata Fischer da Silveira Kroeff $\odot^{2}$

1 Universidade Federal do Maranhão, Centro de Ciências Sociais, São Luís, MA, Brasil. ¿Universidade Federal do Rio Grande do Sul, Porto Alegre, RS, Brasil.

\section{RESUMO}

Considerando a profissão docente uma construção permanente, dar visibilidade aos movimentos de autoprodução dos estagiários do curso de pedagogia em relação à profissão, por meio dos portfólios de aprendizagem do estágio, pode ser um exercício interessante, por compreender que as narrativas e/ou escritos dos aprendentes da docência são expressões de suas vivências, logo de suas construções e reconstruções de si e da profissão. Este texto discute o que consideramos autoprodução docente nos escritos de portfólios de aprendizagem no contexto do estágio em docência em um curso de pedagogia a partir da teoria da autopoiese. Nesse percurso, abordamos as contribuições da teoria de autopoiese e do estudo das narrativas de formação para pensar a constituição de uma identidade docente sempre em processo. Concluiu-se na análise dos portfólios que esse movimento de escrita estimula o processo de autoprodução do profissional docente.

Palavras-chave: Autopoiese. Estágio em docência. Portfólios de aprendizagem.

\section{ABSTRACT}

Considering the teaching profession a permanent construction, giving visibility to the self-production movements of the trainees of the pedagogy course in relation to the profession, through the learning portfolios of the internship can be an interesting exercise, because it understands that the narratives and / or writings of the teaching learner are expressions of their experiences, soon of their constructions and reconstructions of themselves and the profession. This paper discusses of what we consider teacher self-production in the writings of learning portfolios in the context of the teaching internship in a pedagogy course based on the theory of autopoiesis. In this course, contributions of the autopoiesis and the study of formation narratives were considered in order to think about the constitution of a teaching identity always in process. It was concluded in the analysis of the portfolios that this movement of writing stimulates the process of self-production of the teaching professional. Keywords: Autopoiesis. Internship in teaching. Learning portfolios. 


\title{
Introdução
}

Escrever, então, é preparar-se para a entrega, para se mostrar impresso, em diversos suportes.

BAPTISTA, 2000, p. 19)

\begin{abstract}
A
escrita é um movimento singular de existir, logo, de concreticidade do exercício de pensar e refletir. Nesse

movimento, nos encontramos e encontramos o que inicialmente nos parece obscuro, nos produzimos e produzimos o que nos cerca, em uma relação recíproca e constante.

A reflexividade da docência, quando percebida por tessituras escritas, ao mesmo tempo em que revela a dinamicidade da constituição dos processos formativos como um todo, possibilita também a captura de recortes propositivos específicos, que retratam as incorporações do sujeito em formação na constituição de uma identidade profissional. A escrita, nesse sentido, estabelece, segundo Blanchot (2010, p. 113), "o movimento da alternativa", de aproximações e afastamentos de nossas ações, reflexões e investigações.

A reflexividade por meio da escrita pode favorecer a superação de praticismos vazios ou racionalidades técnicas abstratas, favorecendo uma compreensão incorporada do processo de construção da identidade docente em que a complexidade de relações entre elementos que compõem a docência torna-se um foco de análise.

A partir dessa perspectiva, traçamos como objetivo neste artigo discutir o que consideramos como autoproduções dos aprendentes da docência presentes em portfólios de aprendizagem do estágio em docência de estudantes de pedagogia de uma instituição de ensino superior. Assim, buscamos contribuições da teoria da autopoiese à discussão da formação docente, analisando a importância do estágio para a aprendizagem da docência e considerando como instrumentos metodológicos os portfólios de aprendizagem por acreditarmos que estes mobilizam reflexividades que visibilizam e convocam processos de autoprodução na formação profissional.
\end{abstract}

\section{Autopoiese e os processos formativos}

Estudar o ser humano em sua integralidade requer considerar os modos como ele se desenvolve e se mantém, ao longo do tempo, nas relações que estabelece com sua circunstância. À medida que consideramos a constituição do sujeito como um processo dinâmico e aberto, sua compreensão torna-se uma tarefa complexa, pois envolve a experiência contínua de sua corporeidade, a percepção de si, seus pensamentos e emoções, entre outros aspectos.

Nessa perspectiva, novos enfoques têm sido empreendidos nas mais diversas áreas de conhecimento. Nas ciências cognitivas, a teoria da autopoiese de Maturana e Varela (1997) delineia o caráter de autoprodução do ser 
humano considerando-o um sistema em constante transformação. Os autores propõem que a principal característica do ser vivo é sua capacidade de produzir continuamente os componentes que o especificam como unidade em relação a um meio circundante. Esse processo de autoprodução (autopoiese) é então responsável por conseguirmos distinguir um sujeito como um sistema autônomo biopsicossocial, que se constitui e se mantém mediante à permanência do acoplamento estrutural com sua circunstância. Um movimento incessante que constitui sujeito e objeto (mundo) simultaneamente, a partir de mútuas perturbações (MATURANA; VARELA, 2001), e ambos como efeitos, e não polos preexistentes à atividade cognitiva (KASTRUP, 1999). Tal correspondência entre interno-externo não é uma vinculação sucessiva, mas sim dinâmica de coengendramento, uma vez que o movimento de distinção do meio possibilita, ao mesmo tempo, a dinâmica de constante relação com ele.

Essa forma de abordar o problema da cognição recusa a concepção do mundo como uma realidade exterior e pré-dada, a qual somente seria possível acessar por meio de representações (KASTRUP; TEDESCO; PASSOS, 2008), assim como valoriza a dimensão corporal dos processos cognitivos, afirmando a inseparabilidade entre corpo, mente e meio, visto que desde sempre encontramo-nos integralmente imersos no mundo e com ele nos constituímos mutuamente (MATURANA; VARELA, 1997, 2001). O processo de conhecimento sempre se encontra relacionado à história de ações biológicas, sociais e culturais que propiciam as condições da invenção do sujeito como observador de si e de sua circunstância.

Em outras palavras, conhecer/aprender para a teoria da autopoiese acontece como efeito do acoplamento entre o sujeito e a sua circunstância. Todo o conhecimento é uma ação incorporada, sendo o termo "incorporada" referente ao fato de a cognição depender dos tipos de experiência decorrentes de se ter um corpo com capacidades sensóriomotoras e de estas capacidades emergirem acopladas àquilo que definimos, no papel de observadores, como sendo um contexto biológico, psicológico e cultural mais abrangente; ao mesmo tempo em que o termo "ação" enfatiza que os processos sensoriais e motores (percepção e ação) são fundamentalmente inseparáveis da cognição vivida (VARELA; THOMPSON; ROSCH, 2003).

O sujeito possui capacidades e mecanismos cognitivos que performam um processo constante de invenção de si e do mundo sem que o resultado de cada ação cognitiva possa ser determinado de antemão. Dessa forma, parte-se da premissa de que a ação de conhecer/aprender é um processo que envolve a experiência incorporada do sujeito em seu mundo no movimento de autoprodução que é próprio da vida. Tais proposições rompem com os modelos tradicionais de educação, que sugerem a cognição como um processo de aquisição de informações, tendo como finalidade a resolução de problemas mediante a manipulação de representações (conteúdos aprendidos) que são produzidas no contato com um mundo pré-dado, ou seja, um contexto compreendido como independente ao sujeito que conhece. 
Em uma perspectiva autopoiética, a cognição emerge no acoplamento entre o sujeito e seu contexto, configurando as capacidades que o sujeito possui para lidar com o que se constitui como perturbação a sua estrutura. É indispensável então considerar que as interações e as circunstâncias têm papéis de destaque nas operações cognitivas, quando potencializam e promovem a continuidade dos processos de conhecer/aprender. É o que nos lembram Moraes e La Torre (2004, p. 12), em texto que discutem o reencantamento da educação pela autopoiese, colocando que

[...] as circunstâncias atuam sobre o indivíduo e este atua sobre elas, gerando assim uma história de interações recorrentes onde a estrutura do indivíduo vai mudando continuamente em função de sua plasticidade com o meio. Isto significa que nesse processo de interação ocorrem mudanças estruturais internas de acordo com as circunstâncias presentes, ou melhor, de acordo com a relação organismo/meio, onde um afeta o outro a partir de encontros estruturais entre os componentes que interagem.

Embora com essa inscrição bem demarcada no processo autopoietico, as interações não anulam a autonomia dos sujeitos em seus processos constitutivos, pelo contrário, é na interação que as identidades são produzidas e fornecem um caráter único a cada indivíduo. Embora o histórico de acoplamentos com o meio seja importante, o resultado de cada perturbação é definido sempre pela condição atual do sujeito, ou seja, os efeitos das interações são definidos pela estrutura presente do próprio sujeito e não pelo elemento externo de onde provém a perturbação. Nesse sentido, a dependência das interações e a autonomia se entrecruzam e tornam-se instâncias complementares.

Partindo desse parâmetro, nos processos formativos institucionalizados, deveríamos privilegiar a invenção em detrimento da reprodução e, por conseguinte, avançaríamos na concepção de aprendizagem, aproximando-a do fundamento de processo e inacabamento que a autopoiese sugere, que tem na experiência produzida seu campo de legitimação. Sobre isso, Kastrup (2001, p. 17) nos diz que

[...] a aprendizagem não é entendida como passagem do não saber ao saber, não fornece apenas condições empíricas do saber, nem é uma transição ou preparação que desaparece com a solução ou resultado. Aprendizagem é, sobretudo, invenção de problemas, é experiência de problematização.

Nesse viés, o desafio posto para as instituições formativas está vislumbrado na criação de alternativas que tenham nas diversas experiências dos sujeitos o fio condutor de sua proposição, visto serem as experiências produzidas e produtoras das teias de relações dos sujeitos, que correspondem à própria vida do sujeito. A experiência é expressão da vida e deve ser encarada como condição imanente do conhecimento/aprendizagem, como dito anteriormente. 
Pensando especificamente essa experiência na docência, a seguir, abordamos o papel do estágio para a formação do professor, questão imprescindível para situar a relação imbricada e constituinte de ser e estar na profissão.

\section{O estágio como experimentação da profissão}

A profissão docente não é um processo dado, e sim uma construção. Por ser uma profissão que sugere envolvimento intenso na experimentação, tem características que requerem posicionamentos constantes dos sujeitos em uma dada realidade. Esse fato releva a não possibilidade de dissociação da dimensão pessoal nas intervenções profissionais que promova. A dimensão pessoal está alicerçada na mobilização de todos os atributos dos sujeitos - o que são e o que têm - que dão forma e concreticidade a uma ação.

Acreditamos que esse princípio deve permear todas as nuances da formação, principalmente no momento do estágio, que representa uma oportunidade enriquecedora que os alunos têm para observar, refletir e atuar na realidade escolar, visando à construção de sua identidade docente. Para Zabalza (2014, p.243), "uma das contribuições importantes do estágio, como primeiro contato com a profissão, é que permite aos estudantes fazerem uma checagem pessoal sobre seus pontos fortes e fracos em relação às atividades profissionais as quais pretende se incorporar", efetivando a profissionalidade docente, observada na forma como cada um constrói os significados da profissão.

A docência é uma atividade que produz o sujeito e é produzida por ele. Nesse sentido, o estágio ganha complexidade, visto não se tratar de mero exercício técnico da profissão ou experimentação descompromissada, mas de um campo de conhecimento produzido nas interações e práticas sociais da profissão, neste caso, da prática docente. Nesse limiar, se faz necessário considerar a definição de prática docente na qual nos baseamos, caracterizada como atividade de ensino que, para Pimenta (2005, p. 18), se constitui

como contribuição ao processo de humanização dos alunos historicamente situados, espera-se da licenciatura que desenvolva nos alunos conhecimentos e habilidades, atitudes e valores que lhes possibilitem permanentemente irem construindo seus saberes-fazeres docentes a partir das necessidades e desafios que o ensino como prática social lhes coloca no cotidiano.

Nessa perspectiva, Veiga (2001, p.1) define o ensino como uma "prática social concreta, dinâmica, multidimensional, interativa, sempre inédita e imprevisível. É um processo que sofre influências de aspectos econômicos, psicológicos, técnicos, culturais, éticos, políticos, institucionais, afetivos, estéticos". Em consonância, 
o estágio é substancialmente um fazer, que supera a passividade e refere-se a escolhas de objetivos, metodologias e instrumentos para que o processo ocorra, que por sua vez supõe consciência, saberes e conhecimentos entrelaçados e disponibilizados nesse fazer. É, sobretudo, um fazer social que carrega múltiplas dimensões em suas composição e ressonâncias.

Nesse entendimento, o estágio nos cursos de formação de professores precisa ser problematizado na relação entre teoria e prática ao longo de todo curso, o que envolverá considerar todas as dimensões que constitui o sujeito/ professor em formação. Suas ações nos diversos âmbitos sociais desenham perspectivas e alternativas de construção da sua identidade docente, no exercício de reflexão e reconstrução permanente da prática.

A identidade profissional constrói-se pelo significado que cada professor, enquanto ator e autor, confere à atividade docente no seu cotidiano, com base em seus valores, em seu modo de situar-se no mundo, em sua história de vida, em suas representações, em seus saberes, em suas angústias e anseios, no sentido que tem em sua vida o ser professor (PIMENTA; ANASTASIOU, 2002, p. 77).

O estágio é um momento privilegiado da formação por reunir dois espaços/tempos do sujeito, a formação proporcionada na universidade e a ações desenvolvidas nas escolas de educação básica. No intercâmbio desses espaços/tempos, os aprendizes da docência são desafiados constantemente a construírem aprendizagens significativas durante o próprio processo, recorrendo a caminhos e saberes adquiridos anteriormente em outras experiências de prática pedagógica, que, no dizer de Gómez (2000, p. 85), é “uma rede viva de troca, criação e transformação de significados".

Essa perspectiva diacrônica realizada nesse intercâmbio traduz a ideia de não hierarquizar situações ou saberes nesse processo formativo, pois a identidade é construída justamente no diálogo e nas reverberações dos processos vivenciados. Essa relação essencial favorece o desenvolvimento de "um reflexo de aprendizagem permanente que permita aprender a identificar o que é necessário saber e a aprender a aprender com a experiência" (CANÁRIO, 2001, p. 35).

Em um exercício de reflexividade, a narrativa de formação docente desempenha, então, o papel de fio condutor para o conhecimento de si e da profissão, que acontece no registro das experiências, pois a linguagem empregada na ação de narrar "permite a quem opera nela descrever-se a si mesmo e as suas circunstâncias" (MATURANA; VARELA, 2001, p. 232).

Em referência à narrativa de formação e à linguagem enquanto recursos que favorecem o inscrever-se em um processo, tratamos a seguir de situar os portfólios de aprendizagem no limiar dessa perspectiva. 


\section{Os portfólios de aprendizagens}

Pelo prisma da autopoiese, a linguagem ganha ênfase, por referir-se a um recurso que constitui o humano, não se desvencilha da ação e expressa os percursos em que perturbações e acoplamentos foram produzidos, marcando a interação, a constituição e a aprendizagem dos sujeitos. É o que nos dizem Moraes e La Torre (2004, p. 9), ao discutirem o papel da linguagem sob o olhar de Maturana.

Toda realização humana se explica a partir da linguagem e o que não ocorre no seu âmbito, não se poderia chamar de realização humana. Por sua vez, a linguagem somente existe através de um processo de interações recorrentes que surgem em nossa corporeidade, a partir do acoplamento estrutural que existe entre indivíduo e o meio. O gesto, a fala, o som, a postura emergem no fluir recursivo de coordenações consensuais (conversações) que constituem a linguagem.

A linguagem é compreendida aqui como um processo complexo da emergência de estabilidades advindas das coordenações de ações efetuadas em um espaço social, a partir do acoplamento estrutural ontogênico entre os agentes em interação. As distinções que são realizadas por um observador são operações na linguagem. Ao descreverem sua compreensão de linguagem, Maturana e Varela (2001) consideram que o "linguajar" não é um sistema de operações com símbolos abstratos na comunicação, o que diferencia sua forma de abordar a cognição da teoria cognitivista em um de seus pressupostos centrais: a representação. Para os autores, o linguajar emerge através das interações corporais entre duas ou mais pessoas, que efetuam interações recorrentes operando em uma rede de coordenações cruzadas, recursivas e consensuais, ou seja, ela acontece no fluxo de suas coordenações consensuais de ações.

Dessa forma, os símbolos não preexistem à linguagem, mas surgem com ela, no processo de formação das distinções feitas pelo(s) sujeito(s) na ação de observar. Essa perspectiva tem como desdobramento a compreensão de que a linguagem apresenta sempre um caráter coletivo e ativo, pois são os acoplamentos sociais que estabelecem as condições de sua emergência. O significado não se encontra em elementos pertencentes ao ambiente ou na dinâmica interna do agente, mas pertence ao domínio relacional estabelecido entre os dois (DI PAOLO; ROHDE; DE JAEGHER, 2010).

Os registros dos portfólios apresentam os momentos marcantes do que foi experienciado, revelando quais foram e como cada acontecimento teve impacto, bem como os conhecimentos mobilizados para ação do sujeito que narra o processo formativo. Nesse sentido, a narrativa é (auto)formativa, ao deslocar a atenção para o sujeito e seus processos constituintes. $\mathrm{O}$ momento em que o aprendiz questiona sobre seu próprio processo de conhecer resulta na ocorrência 
de uma circularidade autorreferente, um movimento de reflexão no voltar-se a si como instrumento de análise do próprio processo de conhecer (MATURANA; VARELA, 2001).

Em consonância com essa natureza (auto)formativa das narrativas, Josso (2010, p. 71), afirma que "formamo-nos quando integramos na nossa consciência, e nas nossas atividades, aprendizagens, descobertas e significados efetuados de maneira fortuita ou organizada, em qualquer espaço social, na intimidade com nós próprios ou com a natureza", o que nos aproxima da compreensão da profissão como constituição do aprender a ser em processo, na ocasião em que o narrador organiza, controla e mobiliza estratégias autorregulatórias, que estimulam sua reflexibilidade e, por conseguinte, o entrelaçamento de sua aprendizagem.

É no limiar da autorregulação que as aprendizagens da/na docência acontecem, nos trâmites pelos quais o conhecimento da profissão, desencadeado nas situações, se constrói na ação. No campo da formação de professores, as narrativas de formação podem ser vislumbradas na perspectiva dessa autorregulação, ao estimular as subjetivações dos discursos, controle e consciência dos processos próprios, pois é na escrita das experiências que a produção de sentidos em relação ao que foi vivido é construído e exposto. O exercício de narrar compreende o desenvolvimento de um novo processo que abrange a reformulação da experiência narrada.

No contexto das narrativas de formação, os portfólios são considerados instrumentos importantes, ao permitirem, no dizer de Veiga Simão e Flores (2006, p. 257), que os aprendizes "analisem, organizem e explicitem processos de aprendizagem de caráter diverso, desde conceitos científicos até conceitos mais pessoais de natureza autorreflexiva". Por isso, apresentam um potencial singular para estimular aprendizagens que considerem a perspectiva inventiva presente na abordagem da experiência vivida segundo a teoria da autopoiese.

No entendimento de Passeggi (2011), a experiência se constitui na relação entre os acontecimentos e seus impactos nos sujeitos. Embora ainda incipientes na formação de professores, os estudos com esse viés buscam os significados da experiência e dão outra conotação à cognição e às práticas pedagógicas, ampliando o foco para a compreensão dos sentidos que são construídos em cada situação. E os sentidos e significados construídos em relação aos acontecimentos narrados é a própria experiência, visto que a experiência não é uma representação a partir de algo que aconteceu, e sim o próprio acontecimento, o que houve, o que nos atravessou, nos tocou e nos modificou.

Consideramos que aqui reside a importância das narrativas e dos instrumentos utilizados para compreender a formação de professores, em uma tentativa de dar voz aos sujeitos aprendentes da docência, que fornecerá conhecimentos mais alusivos à profissão, a partir do estatuto da experiência, considerando que a "narrativização das práticas seria uma 'maneira de fazer' textual, com seus procedimentos e táticas próprios" (CERTEAU, 2007, p. 152).

Esse fazer textual valoriza o que é experimentado provocando sua reflexão de forma a dimensionar o que ocorreu e tocou o sujeito da ação, em uma relação de diálogo consigo e com os outros. É um mecanismo autoformativo, visto 
ser o sujeito que seleciona, organiza, mobiliza e regula seus pensamentos que caracterizam as aprendizagens. Nesse sentido, os portfólios de aprendizagem do estágio utilizados na formação inicial de estudantes de pedagogia são instrumentos que evidenciam esses aspectos destacados e ajudam na compreensão dos processos autorregulatórios dos estudantes.

Sobre o conceito de portfólio, Frison e Simão (2011, p. 199), estudando as narrativas de formação inicial de professores, dilucidam este recurso como um instrumento metodológico aberto que agrega "ideias, conhecimentos, posturas e outras formas de se desenvolver o trabalho na escola, o que permitiu compreender, com mais clareza, a realidade escolar e o desenvolvimento das competências autoformativas".

Nesses entrelaçamentos, enquadramos os portfólios de aprendizagem dentro dessa concepção de linguagem na autopoiese, que no dizer de Oliveira (2000, p. 148) anuncia seu "duplo papel: gerar as regularidades próprias do acoplamento estrutural social humano e constituir a dinâmica recursiva do acoplamento socioestrutural, produzindo a nossa reflexibilidade". Com isso, nossa intenção a seguir é destacar os escritos dos sujeitos em seus processos formativos como recursos que conduzem a (auto)formação docente.

\section{Os escritos dos aprendentes da docência}

A escrita é uma maneira de expressão do sujeito. Essa expressão o inscreve em um modo processual de constituirse, que "não é algo banal, casual; ao contrário, representa a inscrição complexa do próprio ser e, como resultado, a sua reinscrição" (BAPTISTA, 2000, p. 22). Para trazer à tona as dimensões do estágio, lançamos a questão "o que o estágio representa para você?", para que pudesse ser respondida de forma livre, contudo, pretensiosa, na captação das aprendizagens construídas a partir do exercício de escrita dos portfólios pelos estagiários do curso de pedagogia de uma instituição de ensino superior no segundo semestre de 2017.

Essa questão foi lançada já no primeiro encontro do componente curricular Estágio em Docência na Educação Infantil e Anos Iniciais, que engloba momentos na universidade e também em escolas da rede pública de ensino, corroborando o desenvolvimento da profissionalidade docente, instigando reflexões sobre a escola e a prática docente, com observação, pesquisa, atuação e registro da própria vivência.

$\mathrm{O}$ intuito ao propor à escrita esse questionamento inicial foi dar possibilidade aos aprendentes da docência para que construíssem reflexões desde o início, bem como o movimento de reescrita a partir das experiências ao longo de todo semestre, que poderiam favorecer o dar-se conta dos construtos de si e da profissão. Importante destacar também que as reflexões foram compartilhadas na turma durante as aulas na universidade, conferindo uma troca de impressões e significações importantes ao processo formativo de cada um e do coletivo. 
Selecionamos um total de seis portfólios. O critério de escolha desses escritos se deu por trazerem a tona mais claramente às aprendizagens da docência e seus significados, bem como os esforços conjugados pelos estagiários durante imersão nos espaços escolares. Optamos, na apresentação dos escritos, por manter o anonimato, adotando numeração de 1 a 6 para identificá-los.

Assim, trazemos ao corpus desse texto excertos das impressões, sentimentos e reflexões que foram desenvolvidas e incorporadas pelos aprendentes no momento da escrita dos significados do estágio para sua formação docente. Sabemos que cada sujeito adota um determinado prisma ao comentar suas vivências, ou, no dizer de Freitas (2002, p. 37), "cada pessoa tem um determinado horizonte social orientador de sua compreensão, que lhe permite uma leitura dos acontecimentos e do outro impregnada pelo lugar de onde fala". Dito isto, vamos aos portfólios, destacados por categorias.

\section{As percepções e concepções do estágio}

Os escritos dos sujeitos 1, 2 e 3 encontram-se enviesados em mudanças. Mudanças nas impressões e conceituais que foram construídas sobre o estágio, a partir do contato com as escolas. Vejamos o escrito do sujeito 1.

No momento em que o aluno de graduação tem seu primeiro contato com o estágio, significa que ali ele está finalmente entrando em contato com a realidade da qual ouviu falar tantas vezes dentro das salas da universidade. Ele adentrará como sujeito ativo e poderá finalmente colocar em prática tudo aquilo que foi aprendido, unindo seus saberes teóricos com os saberes práticos que são adquiridos, para alguns durante seus trabalhos anteriores, para outros no decorrer do próprio estágio por não terem trabalhado, ou possuir algum contato com a área anteriormente. Nesse pressuposto, o estágio se torna significativo para mim no momento em que consigo refletir sobre as práticas adotadas pelas professoras regentes das salas de aula, assim como também pelas práticas que foram adotadas por mim dentro do período de regência e que me fizeram refletir acerca das atividades que seriam mais adequadas para cada turma, e que caminho tomar para que a aula não ficasse monótona e sem vida. Entretanto embora tenha havido infortúnios, também houve momentos significativos e que fizeram a diferença, cito tanto um passeio ecológico feito com ambas as turmas, os momentos de contação de histórias e a montagem de um documentário sobre o meio ambiente, pois pude perceber que através de atividades que usem o novo, o tecnológico, aquilo que eles estão acostumados a ver envolve-os e torna aquela atividade significativa não só para mim quanto para eles. Concluo dizendo que minhas experiências com o estágio tanto na educação infantil quanto no ensino fundamental foram boas, pois me fizeram refletir sobre o que realmente é a prática docente e que tipo de educador eu quero ser quando for para o mercado de trabalho. (SUJEITO 1) ${ }^{1}$

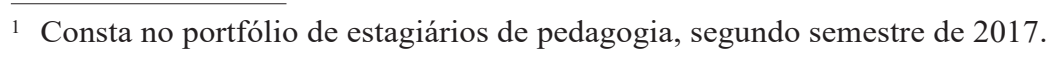


Nesse escrito, para além dos sentimentos positivos e negativos destacados pelo estagiário, parece-nos que a interação com os sujeitos da instituição escolar por meio do estágio o fez encarar algumas situações de forma diferente, a exemplo do aluno da escola como um sujeito ativo, que precisava ser mais bem estimulado em suas potencialidades. Esse destaque do estagiário marca a aprendizagem e a identidade da docência nesse viés, pois foi sua inserção na escola que engendrou confrontos e reconstruções sobre o papel do outro em suas tramas inventivas da profissão. Nesse sentido, resgatamos Baptista (2000), que, discutindo a teoria de Varela, argumenta sobre os processos de escrita, diz que são essas expressões criadas e recriadas nos encontros com o outro. Considerando a coexistência dos sujeitos, a escrita aqui revelou a conjunção com o outro no esboço de si mesmo.

$\mathrm{Na}$ escrita do sujeito 2, as etapas e concepções do estágio foram bem marcantes, revelando em que se fundamentou a condução do estágio.

$\mathrm{O}$ ato de estagiar requer do acadêmico esforço e dedicação. Não é uma prática fácil, pois todo dia, além de cumprir a carga horária determinada, enfrentamos os desafios e as necessidades na escola e da sala de aula. Cada turma possui suas peculiaridades e rotinas nas quais devemos muitas vezes nos adaptar, mas com a ajuda das professoras e do corpo de profissionais da escola conseguimos realizar nosso trabalho. É na observação e na regência que desenvolvemos nossas habilidades e praticamos a teoria estudada por longos períodos na Universidade. A prática da observação para o campo do estágio se faz necessária com a intervenção e a utilização da mesma no campo, nela passamos a perceber os "erros" e "falhas" das práticas profissionais, onde juntamente com a prática do estágio podemos trazer possíveis soluções para os diversos dilemas da realidade escolar. Assim, como estagiária não estive na sala apenas para avaliar e determinar o grau do fracasso escolar, mas através da observação e regência obter maior compreensão da complexidade da prática do estágio. $\mathrm{O}$ apoio dos professores supervisores nesse processo também se torna fundamental e nos auxilia na busca por respostas aos conflitos e dificuldades que surgem. Nesse ínterim, o aluno estagiário em sala de aula é um ser que promove a prática social, ou seja, ali ele exerce sua função como educador e expõe seu conhecimento adquirido na academia. Dessa forma a teoria e a prática são ações que devem ser apreendidas juntas de forma que o uso das mesmas venha amadurecer as estruturas do conhecimento e das atividades que o aluno irá desenvolver em sala. Em suma, a teoria e a prática precisam ser inseparáveis e indissociáveis, assim como a pesquisa precisa ser utilizada também na área do estágio onde o papel de cada processo nesse conjunto fortalecerá a experiência profissional, além de contribuir para a facilitação e compreensão do conhecimento e da prática de intervenção. (SUJEITO 2) ${ }^{2}$

${ }_{2}$ Consta no portfólio estagiários de pedagogia, segundo semestre de 2017.

Educação Por Escrito, Porto Alegre, v. 10, n. 1, jan.-jun. 2019: e32358 
Aqui, a articulação entre teoria e prática pode desencadear intervenções mais maduras, bem como legitimar um conhecimento mais fundamentado sobre a profissão docente. É o que nos lembram Pimenta e Lima (2010) sobre os desafios e dificuldades suscitados pela rotina do estágio.

Em relação ao sujeito 3, as percepções e articulações que traz na escrita nos aproxima do que argumenta Benjamin (1994), quando refere que o que está sendo narrado não se constitui somente como transmissão de informações, e sim como uma partilha do que fora significativo, compartilhamento de quem é o sujeito e o que se tornou a partir do que vivenciou.

O estágio se tornou ainda mais importante para mim pelo fato de não ter nenhuma experiência em sala de aula, é o encontro com o novo, com o desconhecido, com uma realidade cheia de desafios e dificuldades, essa foi a oportunidade para que eu pudesse fazer uma reflexão acerca do processo educativo, como ele acontece de fato, e todas as dificuldades encontradas para se chegar a um resultado satisfatório no que se refere a aprendizagem dos alunos. Na Educação Infantil pude perceber o quanto essa fase é extremamente importante na formação da criança como indivíduo participante do meio social. E torna-se um desafio formar essas crianças, levando em consideração as peculiaridades de cada uma, mas sem dúvida uma proposta diversificada e bem elaborada é capaz de superar estes desafios. Nessa etapa da educação é perceptível a necessidade de um trabalho dinâmico, que aborde atividades como contação de histórias, rodas de conversa, jogos, brincadeiras, pinturas, desenhos. Sempre explorando todo o conhecimento que as crianças possuem, fazendo delas seres ativos no processo de aprendizagem. Há uma infinita gama de possibilidades para auxiliar no desenvolvimento pleno das crianças. Nos Anos Iniciais nos deparamos com crianças que estão num processo de aquisição da leitura e da escrita, momento tão significativo no processo educativo, elas têm uma disponibilidade para aprender mais, querem coisas novas, querem palavras novas, querem descobrir o mundo que os cerca através das palavras. É notório o desejo em aprender, e na prática do professor podemos visualizar o papel crucial no envolvimento do aluno com o aprendizado. É muito satisfatório perceber a alegria no rosto das crianças ao conseguir escrever ou ler uma nova palavra, cada pequena conquista faz toda a diferença. Por fim, posso dizer que em toda a minha caminhada universitária essa foi a experiência mais rica, conviver diariamente com as crianças em sala de aula fazendo uma troca mútua de conhecimentos acrescentou de forma muito significativa na minha formação, não apenas como futura pedagoga, mas como pessoa. Essa experiência pode me mostrar claramente o que é ser professor, foi na sala de aula que tive um aperfeiçoamento prático para que futuramente possa exercer da melhor maneira possível o papel de professor. E é nessa perspectiva que ressalto mais uma vez a extrema necessidade e importância dos estágios na formação de qualquer profissional, como momento de enriquecimento e aprimoramento dos conhecimentos obtidos através das teorias. (SUJEITO 3) ${ }^{3}$

3 Consta no portfólio estagiários de pedagogia, segundo semestre de 2017 
Ao destacar a relevância da vivência do estágio nos aspectos pessoal e profissional, pensamos que descobertas incorporadas sobre a profissão marcam esse escrito. No quesito falta de experiência docente, vale destacar mais uma vez Pimenta e Lima (2010), quando comentam que o estágio pode convergir para vivencias pedagógicas que desencadeiam aprendizagens da profissão.

\section{O sentipensar a educação}

Por ser uma profissão de interações, as emoções estão sempre imanentes em toda e qualquer intervenção, é o que aborda o sujeito 4.

A experiência do Estágio Supervisionado em Educação Infantil e Anos Iniciais me proporcionou uma vivência ímpar de reflexão da realidade escolar e sobretudo da dinâmica em sala de aula. A partir do processo de observação, pude compreender o quão essencial é este momento na compreensão da cultura organizacional da escola e as peculiaridades da própria sala de aula para a definição de um plano de atividades com metodologias que respeitem a dinâmica da instituição, ao passo em que também colocam o aluno como centro e sujeito do processo de aprendizagem. Definitivamente, a experiência nos Anos Iniciais foi a mais desafiadora, por ser um espaço em que eu já tinha atuado, mas que exigiu maiores reflexões no sentido de avançar para novas tentativas de lidar com as peculiaridades de turma. $\mathrm{O}$ auxílio da professora foi diferenciado em ambas as turmas. Na Educação Infantil a professora aparentou estar um pouco desconfortável no momento da nossa observação, mas nos deixou plenamente livres no momento da regência, fazendo apenas a exigência do uso da apostila todos os dias. A liberdade em sala de aula foi essencial, porém sentimos falta de um maior suporte por parte da professora, no sentido de facilitar as atividades propostas, e de intervir positivamente, quando necessário. Já nos Anos Iniciais a professora se apresentou sempre muito confortável com nossa presença, nos envolvendo ao máximo nas atividades, mesmo durante o período de observação. Não nos deu total liberdade em sala de aula no momento da regência, pois já tinha um cronograma de atividades previamente definido. Porém, sempre abriu espaço para nossas sugestões e contribuições, ao passo em que também auxiliou positivamente quando estávamos à frente da turma. Entendi essa intervenção da mesma como um ponto positivo no nosso avanço pessoal e profissional, pois melhor que estar neutra em relação ao desenvolvimento das metodologias desenvolvidas pelo grupo, é intervir de modo a primar por uma melhor execução em oportunidades futuras, fato este que demonstra também certa preocupação da professora com nosso desempenho em sala de aula. O aspecto mais peculiar e comum nas duas etapas de ensino foram os laços de afetividade criados no decorrer do processo, o que acabou por ocasionar despedidas sempre muito emocionantes, onde foi possível ratificar o 
aspecto humanizador da profissão, e o envolvimento, voluntário ou involuntário, que é base para o mesmo. Por fim, a experiência foi a mais significativa que já pude viver durante todo o meu período de formação, por seu caráter desafiador e instigante, abrindo espaço para reflexões diárias. Despertou também para a reflexão sobre quão essencial é esta experiência para o processo de formação do acadêmico, sendo gritante a necessidade de modificação da grade do curso, no sentido de proporcionar experiências como estas aos mesmos no decorrer de todo o curso, e não apenas no final, objetivando fazer com que os acadêmicos se reconheçam mais previamente na profissão, e tenham mais tempo para aperfeiçoar suas práticas de reflexão de diferentes realidades educacionais. (SUJEITO 4)

Associamos esse aspecto destacado pelo sujeito 4 ao que fora estudado por Moraes e La Torre (2004), ao discutirem o sentipensar na educação a partir da teoria da autopoiese. Maturana (2001) aborda as emoções como disposições corporais dinâmicas, que definem o domínio no qual uma ação acontece. Assim, as emoções especificam os domínios de ação nos quais operamos a cada instante, porque toda ação é realizada em um domínio emocional específico. Nossas emoções guiam momento a momento nosso agir ao especificar o domínio relacional em que operamos a cada instante. $\mathrm{O}$ ato de pensar, por exemplo, pressupõe um encontro, um impacto afetivo-emotivo, que não se acrescenta ao pensamento como um colorido, mas cria as próprias condições para que o pensamento ocorra. Assim, não se trata somente da manifestação de uma emoção íntima que é expressada, mas a expressão da emoção como articulação de uma experiência-mundo (ROCHA; KASTRUP, 2009).

Segundo Moraes e La Torre (2004, p. 5), “é o fluir contínuo das emoções que modela o nosso cotidiano e todo o nosso viver/conviver que constitui o fundamento de tudo que realizamos. Inclusive do nosso sentipensar, lembrando que qualquer fato da vida tem como base fundamental o emocionar”. Nesse sentido, somos seres de emoção, pois até mesmo nossa racionalidade solicita antes emoção para ser delineada.

As emoções constituem a capacidade de transformar e ser transformado. Por outro lado, a experiência de descrever uma emoção nos remete aos modos de expressá-la e distingui-la por meio da linguagem no exercício de sermos observadores de nossa experiência.

\section{A experimentação}

A palavra experiência parece nortear o comentado pelo sujeito 5, que vê no exercício do estágio uma oportunidade de se apropriar da dinâmica escolar, que por sua vez irá subsidiar conhecimentos sobre a profissão.

${ }_{4}$ Consta no portfólio estagiários de pedagogia, segundo semestre de 2017. 
O estágio em sala de aula foi uma etapa muito importante para minha formação acadêmica, profissional e pessoal, pois já exerço a função de professor, mas conhecer outras atuações de profissionais em sala de aula só vem a acrescentar mais minha vivência como educador. A experiência nesse processo de estágio supervisionado em Regência na Educação Infantil e Anos Iniciais permitiu-me observar e vivenciar as ações desenvolvidas pelo professor em sala de aula e dessa forma adquirir mais conhecimentos e métodos educacionais que ajudam na aprendizagem dos alunos. Realizei meu estágio de forma comprometida e atenta. O período na Educação Infantil, confesso, me deixou apreensiva, não imaginei o quão prazeroso seriam esses dias de atuação. Os alunos são muito carinhosos e também têm um potencial e criatividade além do que imaginamos. São crianças ativas, uns mais que outros, umas crianças que merecem atenção especial, por se destacar mais que outras, tanto na aprendizagem, quanto na altivez de ações. Foi um período muito rico e de muita clareza, onde o que mais destacaria é a responsabilidade do professor em relação aos alunos e a importância de reger e direcionar crianças na sua caminhada escolar, de maneira que elas vejam a escola como um lugar de alegria, diversão e de muita aprendizagem. A atuação nos Anos Iniciais ( $2^{\circ}$ ano) também me fez refletir, mas agora na aprendizagem de leitura e escrita. O que às vezes percebe-se é que alguns alunos vão sendo empurrados para as séries seguintes, sem uma devida atenção dos professores anteriores. Não se respeita e se compromete com a aprendizagem dos mesmos. Mas são crianças cheias de energia, que, se bem orientadas, têm uma capacidade enorme de adquirir conhecimentos intelectuais satisfatórios. O período de estágio em sala de aula foi um momento gratificante e reflexivo enquanto ferramenta para o exercício prático do aluno/professor. É a etapa em que o mesmo tem a experiência de vivenciar no cotidiano de uma sala de aula o que na teoria lhe foi apresentada nas aulas da Universidade. Compreendi a importância do estágio na formação do acadêmico. Pois só conhecendo o local de atuação, participando das atividades, fazendo parte, mesmo que por pouco tempo de tudo o que se passa dentro de uma sala de aula, é que o mesmo pode ter uma visão direta da maneira como o trabalho é executado, e o que é mais importante, o aluno/professor pode ser um agente de mudança de futuras atitudes como educador, visando sempre a um ensino de qualidade para com a sociedade, ou seja, depois dessa etapa vivida, ele pode ser um agente transformador do ensino-aprendizagem. (SUJEITO 5) ${ }^{5}$

Segundo Nóvoa (1995), a formação passa pela experimentação, peça pesquisa e pela inovação do trabalho pedagógico. E o que significa experimentar senão o colocar-se e doar-se em uma atividade que o transforma e transforma a circunstância em que opera? A riqueza do estágio está justamente nesse favorecer os saberes pela experiência.

\footnotetext{
5 Consta no portfólio estagiários de pedagogia, segundo semestre de 2017.
} 


\section{0 escrever-se}

Por fim, na escrita do sujeito 6 destacamos as adjeções que acontecem nos encontros produzidos.

Dissertar é uma forma de expor seus pensamentos em torno de um determinado assunto. Estágio: momento de aprendizado. Percebe-se que o estágio é uma das primeiras oportunidades para se trabalhar na prática o que se aprendeu na teoria. Conforme o gráfico de Zabalza (2014), esta prática, que nada mais é que o encontro da teoria com a prática, vai se relacionar com vários outros encontros, os quais abrangerão a vida pessoal e profissional. É um momento em que o acadêmico encontra o setor com que mais se identifica, para futuramente poder trabalhar. Poderá verificar os pontos negativos e positivos da profissão, entendendo que nenhuma é perfeita e que sempre haverá algo que poderá não lhe agradar, mas como bom profissional saberá agir de maneira que venha a resolver o problema ou pelo menos a detectar possíveis soluções. É um encontro com o seu próprio "eu". Será neste momento que o(a) acadêmico(a) se encontrará como profissional, descobrindo um novo espaço para aprendizagem, reconhecendo que a teoria tem uma aproximação significativa da prática. É uma ocasião de encontro com outros profissionais, outras mentalidades, outras ideias, as quais muitas vezes vêm acompanhadas de preconceitos ou ideias preconcebidas que serão diferentes das suas, e que se não estiver preparado(a) poderá abater suas expectativas de trabalho, o que acarretará decepções e às vezes até desânimo. No entanto, estando preparado(a), todas essas ações serão apenas experiências que irão enriquecer a gama dos conhecimentos do(a) acadêmico(a). O estágio é de suma importância para ampliar as experiências práticas, compartilhando o paralelo das teorias X prática. É um encontro consigo mesmo, como pessoa, como profissional e um encontro com o próximo, com ideias semelhantes e/ou não, é um momento de vivenciar um novo aprendizado, o qual será útil para seu novo caminhar. Diante do que observei e vivenciei, confesso que tive um acolhimento muito compreensível. A professora L. me surpreendeu com sua dedicação e forma de trabalhar com as crianças, mesmo sendo uma profissional tão ocupada tirou um momento para me orientar e acompanhar meu estágio, fiquei muito agradecida e pude aprender muito com ela. Organização em primeiro lugar, o que faz com que seu trabalho seja bem feito. Portanto, tudo que presenciei e compartilhei, com trocas de informações pude aumentar os meus conhecimentos e através deste aprendizado ter a consciência que me ajudarão na minha vida profissional, as experiências vividas serão um suporte para ampliar minhas ações numa prática futura não tão longe. (SUJEITO 6) ${ }^{6}$

\footnotetext{
${ }^{6}$ Consta no portfólio estagiários de pedagogia, segundo semestre de 2017.
} 
As descrições trazidas remetem aos objetos do domínio de interações que foram tomados pelo sujeito que narra. Ao tomá-las, o sujeito torna-se observador de seus fazeres, operando na linguagem, processo que nas palavras de Maturana e Varela (2001, p. 234) marca nossa existência, "conservando nossa adaptação no domínio de significados resultante". Nas descrições, a vida - em todos os seus âmbitos, pessoal, acadêmico, profissional - acontece no resultado do nosso histórico de interações, como argumentado pela autopoiese. É nessa interação que os sujeitos conhecem, ao mesmo tempo em que se criam e recriam.

\section{Considerações finais}

Por meio da linguagem podemos produzir descrições e explicar estados subjetivos e relações com outras pessoas. Embora possa se configurar sob diversas formas, como no gesto e na fala, neste estudo abordamos portfólios de aprendizagem como um recurso da linguagem escrita que apresenta as possibilidades de sujeitos contarem um pouco de si, dos percursos que têm feito, das emoções, das conquistas, dos pensamentos, enfim, de refletirem a respeito de seus fazeres no cotidiano do estágio docente.

Trouxemos na discussão sobre a autopoiese os fundamentos da teoria quanto a constituição permanente do ser e o papel da experiência enquanto elemento importante nos processos formativos. Essa experiência é engendrada pelos encontros e acoplamentos que os sujeitos realizam.

Quando tratamos do estágio adotamos a concepção de que a docência e sua identidade são construídas em processos interativos dos sujeitos, sendo, portanto, uma constante e requerendo sempre um movimento dialético de encontros com o outro e consigo mesmo.

Na sessão sobre os portfólios de aprendizagem do estágio, discutimos como as narrativas favorecem e carregam marcas da constituição do ser e da profissão, o que as torna um instrumento que esclarece e legitima aprendizagens.

Nas análises dos escritos dos seis portfólios, percebemos que os estagiários romperam algumas concepções sobre a aprendizagem que dão pistas de percursos alternativos constitutivos de suas identidades docentes. A imersão nas instituições educativas propiciaram que conhecessem e participassem de atividades, construindo e reconstruindo suas intervenções, e provocaram mudanças em si e no ambiente.

Esse movimento anima o processo de produção da identidade docente, que não se origina de imediato, nem é desenvolvida somente com domínio de técnicas ou dada por finalizada. A docência tem sua identidade continuamente construída a partir das interações, e por isso mantém um caráter aberto de possibilidades e continuidades.

A reflexividade contida nos portfólios favorece outros olhares sobre a aprendizagem da docência, traz novas questões em relação à atuação profissional e pode apontar enredos diferentes nas políticas de formação. 


\section{Referências}

BAPTISTA, Maria Luiza Cardinale. Emoção e desejo em processos de escrita rumo a uma educação autopoiética. Novos Olhares, São Paulo, n. 6, p. 18-25, 30 dez. 2000. Disponível em: https://www.revistas.usp.br/novosolhares/article/view/51343. Acesso em: 2 jun. 2018. https://doi.org/10.11606/issn.2238-7714.no.2000.51343

BLANCHOT, Maurice. A conversa infinita: a palavra plural. São Paulo: Escuta, 2001.

BENJAMIN, Walter. Obras escolhidas: magia e técnica, arte e política: ensaios sobre literatura e história da cultura. São Paulo: Brasiliense, 1994. v. 1.

CANÁRIO, Rui. A prática profissional na formação de professores. In: CAMPOS, B. P. Formação profissional de professores no ensino superior. Porto: Porto Editora, 2001. https://doi.org/10.31639/rbpfp.v8i15.142

CERTEAU, Michel de. A Invenção do Cotidiano: 1. Artes de Fazer. Petrópolis: Vozes, 2007.

DI PAOLO, Ezequiel; ROHDE, Marieke; DE JAEGHER, Hanne. Horizons for the enactive mind: Values, social interaction, and play. In: STEWART, John; GAPENNE, Olivier; DI PAOLO, Ezequiel (ed.). Enaction: Toward a new paradigm for cognitive science. Cambridge: MIT Press, 2010. https://doi.org/10.7551/mitpress/9780262014601.003.0003

FREITAS, Maria Teresa de Assunção. A abordagem sócio-histórica como orientadora da pesquisa qualitativa. Cadernos de Pesquisa, São Paulo, n. 116, p.21-39, jul. 2002. https://doi.org/10.1590/s0100-15742002000200002

FRISON, Lourdes Maria Bragagnolo; SIMÃO, Ana Margarida Vieira Veiga. Abordagem (auto)biográfica: narrativas de formação e de autorregulação da aprendizagem reveladas em portfólios reflexivos. Educação, Porto Alegre, v. 34, n. 2, p. 198-206, maio/ago. 2011. Disponível em: http://revistaseletronicas.pucrs.br/ojs/index.php/faced/article/viewFile/8705/6357. Acesso em: 20 maio 2018. https://doi.org/10.35362/rie70173

GÓMEZ, Angel I. Pérez. Ensino para a compreensão. In: SACRISTÁN, José Gimeno; GÓMEZ, Angel I. Pérez. Compreender e transformar o ensino. 4. ed. Porto Alegre: Artmed, 2000.

JOSSO, Marie-Christine. Da formação do sujeito... ao sujeito da formação. In: NÓVOA, António; FINGER, Matthias. O método (auto)biográfico e a formação. Natal: EDUFRN; São Paulo: Paulus, 2010. https://doi.org/10.18593/r.v41i1.9267

KASTRUP, Virgínia. A invenção de si e do mundo: uma introdução do tempo e do coletivo no estudo da cognição. Campinas: Papirus, 1999.

KASTRUP, Virgínia. Aprendizagem, arte e invenção. Psicologia em Estudo, Maringá, v. 6, n. 1, p. 17-27, jan./jun., 2001. https://doi. org/10.1590/s1413-73722001000100003 
KASTRUP, Virgínia; TEDESCO, Silvia; PASSOS, Eduardo. Políticas da cognição. Porto Alegre: Sulina, 2008.

MATURANA, Humberto. Cognição, ciência e vida cotidiana. Belo Horizonte: UFMG, 2001.

MATURANA, Humberto; VARELA, Francisco. A árvore do conhecimento: as bases biológicas da compreensão humana. São Paulo: Palas Athena, 2001.

MATURANA, Humberto; VARELA, Francisco. De máquinas e seres vivos: autopoiese - a organização do vivo. Porto Alegre: Artes Médicas, 1997.

MORAES, Maria Cândida; TORRE, Saturnino de La. Sentipensar sob o olhar autopoiético: Estratégias para reencantar a educação. São Paulo Vozes, 2004.

NÓVOA, Antônio. Os professores e a sua formação. Lisboa: Dom Quixote, 1995.

OLIVEIRA, Lucila Maria Pesce de. Visão educacional eco-sistêmica: uma contribuição a partir de Maturana e Varela. Revista da APG, São Paulo, v. 23, p. 141-154, 2000. Disponível em: http://www.geocities.ws/lucila_mariapesce/publicacoes/ APG_Visao_eco-sistemica.html. Acesso em: 24 maio 2018. https://doi.org/10.11606/issn.2594-5920.primeirosestudos.2001. $1045 \overline{7} 6$

PASSEGGI, Maria da Conceição Botelho Sgadari. A experiência em formação. Revista Educação, Porto Alegre, v. 34, n. 2, p. 147-156, maio/ago. 2011. Disponível em: http://revistaseletronicas.pucrs.br/ojs/index.php/faced/article/view/8697. Acesso em: 20 maio 2018.

PIMENTA, Selma Garrido. Saberes pedagógicos e atividade docente. São Paulo: Cortez, 2005.

PIMENTA, Selma Garrido; ANASTASIOU, Léa das Graças Camargos. Docência no ensino superior. São Paulo: Cortez, 2002.

PIMENTA, Selma Garrido; LIMA, Maria Socorro Lucena. Estágio e Docência. 5. ed. São Paulo: Cortez, 2010.

ROCHA, Jerusa Machado; KASTRUP, Virgínia. Cognição e emoção na dinâmica da dobra afetiva. Psicologia em Estudo, Maringá, v. 14, p. 385-394, jun. 2009. https://doi.org/10.1590/s1413-73722009000200020

VARELA, Francisco; THOMPSON, Evan; ROSCH, Eleonor. Símbolos: a hipótese cognitivista. In: A MENTE incorporada: ciências cognitivas e experiência humana. Porto Alegre: Artmed, 2003.

VEIGA, Ilma Passos Alencastro (org.). Caminhos da profissionalização do magistério. Campinas: Papirus, 2001. 
VEIGA SIMÃO, Ana Margarida; FLORES, Maria Assunção. O aluno universitário: aprender a auto-regular aprendizagem sustentada por dispositivos participativos. Revista Ciências e Letras, Porto Alegre, n. 40, p. 216-29, jul./dez. 2006.

ZABALZA, Miguel Ángel. O estágio e as práticas no contexto de formação universitária. São Paulo: Cortez, 2014.

Recebido em: 28/10/2018.

Aprovado em: 13/7/2019.

Publicado em: 31/12/2019.

\section{Endereço para correspondência:}

Kessia Mileny de Paulo Moura

Universidade Federal do Maranhão, Centro de Ciências Sociais

Rua Urbano Santos - Centro

65900-410, Imperatriz, MA, Brasil

\section{Autores:}

Kessia Mileny de Paulo Moura

Possui graduação em Pedagogia pela Universidade Federal da Paraíba (2003) e Mestrado em Educação pela Universidade Federal da Paraíba (2006). Doutoranda em Informatica na Educação PPGIE/UFRGS. É Professora Assistente no Centro de Ciências Sociais, Saúde e Tecnologia da Universidade Federal do Maranhão, campus de Imperatriz. Tem experiência docentes nas áreas de Sociologia da Educação, Estágio Supervisionado, Avaliação da Aprendizagem, Politicas Educacionais, Informatica Aplicada a Educação e Projeto Educativo.

É Coordenadora do Curso de Pedagogia do Parfor/campus de Imperatriz.

Orcid: https://orcid.org/0000-0002-5124-1432

E-mail: kessiaita@gmail.com

Marie Jane Soares de Carvalho

Pós-Doutorado - UNED/Madrid. (2012). Doutora em Educação pela UFRGS (1999). Estágio de Doutorado na University of Toronto (1997).

Mestre em Educação (1990). Graduação em Pedagogia (1982). Professora Titular do Departamento de Ensino e Currículo, Faculdade de Educação da UFRGS. Docente no Programa de Pós-Graduação em Informática na Educação (PPGIE). Participa como membro de dois grupos do

Conselho Nacional de Pesquisa (CNPq): Inclusão Digital (UPF) e Tempo Sociedade (UFMG). Líder do Grupo de Pesquisa Núcleo de Estudos em Tecnologias Digitais na Educação no CNPq (NETE 2013-). Coordenadora da Plataforma Cultiveduca <http://cultiveduca.ufrgs.br/>.

Desenvolve dois projetos de pesquisa intitulados: Redes Sociais e Cultura da Participação no Contexto da Formação Docente e Desenvolvimento da Plataforma CultivEduca - formar o educador faz toda a diferença. Trabalha com a linha de pesquisa em: Ambientes Informatizados e Currículo a Distância, Arquiteturas Pedagógicas, Análise de Redes Sociais, Formação de Professores. É consultora na área de tecnologias digitais e formação de professores.

Orcid: https://orcid.org/0000-0003-1746-2044

E-mail: marie.jane@ufrgs.br

Endereço: Universidade Federal do Rio Grande do Sul

Rua Sarmento Leite 500 - Centro

90050-170, Porto Alegre, RS, Brasil 


\section{Renata Fischer da Silveira KroefF}

Doutoranda do Programa de Pós-Graduação em Psicologia Social e Institucional (UFRGS). Mestre em Psicologia Social e Institucional (UFRGS).

Especialista em Terapia Sistêmica pelo Centro de Estudos da Família e do Indivíduo (CEFI). Graduada em Psicologia pela Universidade do Vale do

Rio dos Sinos (UNISINOS) e em Licenciatura em Psicologia pela Universidade Federal do Rio Grande do Sul (UFRGS). Professora no Curso de Psicologia

da Faculdade IENH e na Especialização em Terapia Sistêmica Individual, Familiar e de Casal do Centro de Estudos da Família (CEFI Porto Alegre).

Integrante do Núcleo de Ecologias e Políticas Cognitivas e do Projeto Oficinando em Rede na Universidade Federal do Rio Grande do Sul.

Membro do Núcleo de Estudos e Atendimento ao Luto (CORA/CEFI). Temas principais de pesquisa: cognição enativa, formação docente, processos de aprendizagem, psicologia e educação, processos de subjetivação contemporânea, tecnologias da informação e da comunicação (TICs), jogos digitais,

terapia sistêmica, terapia narrativa e clínica psicológica de atendimento ao luto.

Orcid: https://orcid.org/0000-0002-9029-6647

E-mail: kroeff.re@gmail.com 